\title{
Radiochemoimmunotherapy with intensity- modulated concomitant boost: interim analysis of the REACH trial
}

\author{
Alexandra D Jensen ${ }^{1, *^{*}}$, Jürgen Krauss ${ }^{2}$, Karin Potthoff ${ }^{1}$, Christian Simon $^{3}$, Anna V Nikoghosyan ${ }^{1}$, Karen Lossner ${ }^{1}$, \\ Jürgen Debus ${ }^{1}$ and Marc W Münter ${ }^{1}$
}

\begin{abstract}
Purpose: To evaluate efficacy and toxicity clinical in the intensified treatment of locally advanced squamous cell carcinoma of the head and neck (SCCHN) with the combination of chemotherapy, the EGFR antibody cetuximab, and intensity-modulated radiation therapy (IMRT) in a concomitant boost concept.

Methods: REACH is a prospective, bi-centric phase II trial of carboplatin/5-FU and cetuximab weekly combined with IMRT. Primary endpoint is locoregional control, secondary endpoints include acute radiation effects and adverse events. Evaluation of disease response is carried out according to the Response Evaluation Criteria in Solid Tumors (RECIST); toxicity is assessed using NCI CTC $\vee$ 3.0.

Results: Treatment was tolerated moderately well, acneiforme erythema occurred in $74.1 \%$ (grade II/III), mucositis grade III in 28.6\%, and radiation dermatitis grade III in 14.3\%. Higher-grade side-effects resolved quickly until the first follow-up post treatment. Objective response rates were promising with 28.6\% CR at first follow-up and 92.9\% thereafter.

Conclusion: The combination of standard carboplatin/5-FU and cetuximab is feasible and results in promising objective response rates. The use of an IMRT concomitant boost is practicable in a routine clinical setting resulting in only moderate overall toxicity of the regimen.
\end{abstract}

Trial Registration Number: ISRCTN87356938.

Keywords: Radiochemotherapy, Radioimmunotherapy, Cetuximab, IMRT, Concomitant boost, Squamous cell head and neck cancer, SCCHN

\section{Introduction}

Long-term disease control for patients with advanced squamous cell carcinoma of the head and neck (SCCHN) is still challenging. For locally advanced or unresectable SCCHN without evidence of distant metastases, combined radiochemotherapy is the only curative treatment possibility. In the MARCH meta-analysis, concurrent chemoradiotherapy results in an absolute survival benefit of $6.5 \%$ at 5 years with the most effective regimen being simultaneous chemoradiation [1-3]. This effect is mainly caused by an improved local control and only to a lesser

\footnotetext{
* Correspondence: alexandra.jensen@med.uni-heidelberg.de 'Dept of Radiation Oncology, University of Heidelberg, INF 400, 69120 Heidelberg, Germany

Full list of author information is available at the end of the article
}

extent by reduction of distant metastases. In the MARCH data, platin-based regimens were shown to have the highest effect in concurrent chemoradiotherapy [1-3].

Intensified radiotherapy such as altered fractionation schedules also lead to a significant improvement of local control but also overall survival if radiation therapy is performed as a single therapy modality with the highest benefit in hyperfractionated radiotherapy schedules [4]. Adding chemotherapy to altered fractionation radiotherapy also resulted in improved outcome [5].

While intensified treatment regimen - whether as intensified chemoradiation or altered fractionation radiotherapy - have been shown to improve outcome $[4,6]$, it is a clinical fact that a significant percentage of patients are not able to receive their full planned course of treatment due

\section{Biomed Central}

(c) 2012 Jensen et al; licensee BioMed Central Ltd. This is an Open Access article distributed under the terms of the Creative Commons Attribution License (http://creativecommons.org/licenses/by/2.0), which permits unrestricted use, distribution, and reproduction in any medium, provided the original work is properly cited. 
to excessive toxicity, hence the need arises to modify and optimize these regimens.

Various options exist: first of all, the use of more tolerable chemotherapy combinations, second the integration of molecular targeted drugs and third the use of modern concepts of radiotherapy.

Staar et al. combined carboplatin with 5-FU and hyperfractionated accelerated radiotherapy in a randomized phase III trial [7] and presented comparable results to studies based on cisplatin. The published acute and late toxicity was moderate in this trial. Targeted therapy approaches with the EGFR antibody cetuximab have been found to potentiate the effects of chemotherapy and radiotherapy in experimental systems, Bonner and coworkers were the first to establish combined radioimmunotherapy for SCCHN in a definitive setting $[8,9]$. Overall survival and local control were significantly improved in the combination regimen as opposed to the radiotherapy-alone arm. Moreover, no further severe side effects were reported apart from acneiforme skin reactions and a low rate of infusion reactions $[8,9]$. Retrospective comparison of the Bonner data with landmark radiochemotherapy studies suggests comparable results could be achieved with this new combination [10].

Modern radiotherapy techniques such as intensitymodulated radiotherapy (IMRT) and image guidance (IGRT) have rapidly found acceptance in the routine treatment of SCCHN. Intensity-modulated radiotherapy (IMRT) has been shown to reduce acute and late toxicity [11] and prevent long-term sequelae such as higher-grade xerostomia by improved normal tissue sparing and preservation of saliva flow $[12,13]$. Improved normal tissue sparing permits relative dose escalation to the tumor in order to improve local control and patient outcome [14].

REACH combines all of these approaches: systemic treatment is intensified by the combination of chemotherapy and EGFR antibody treatment (carboplatin/ 5-FU and cetuximab) while local treatment is intensified by a concomitant boost concept in IMRT technique.

Aim of the trial is to evaluate disease control, toxicity, and feasibility of this intensified triple-therapy.

\section{Methods}

\section{Patients}

Patients with pathologically confirmed, locally advanced non-metastatic squamous cell cancer of oropharynx, hypopharynx, or larynx were eligible for the trial. Age between 18 and 70 years, Karnofsky performance score of $>70 \%$, and adequate bone marrow, liver, and renal function were also required. Exclusion criteria were nasopharyngeal carcinoma, prior chemotherapy, radiotherapy, or exposure to EGFR pathway targeting therapy [15].

Work-up included complete panendoscopy, diagnostic CT scans of the neck and chest, abdominal ultrasound, and bone scan. In the absence of contraindications, all patients received diagnostic MRI scans for treatment planning and follow-up.

The trial was reviewed and approved by the University of Heidelberg Medical School Ethics Committee; informed consent was obtained from all patients prior to inclusion.

\section{Immunotherapy}

Patients received the loading dose cetuximab one week prior to RT (d1) at the recommended dose of $400 \mathrm{mg} /$ $\mathrm{m}^{2}$ body surface followed by weekly infusions with $250 \mathrm{mg} / \mathrm{m}^{2}$. All patients received $8 \mathrm{mg}$ dexamethasone and $4 \mathrm{mg}$ dimetinden prior to each application of cetuximab. Missed out doses of cetuximab during the treatment course are to be omitted. Cetuximab-induced skin reactions are treated according to standard in-house protocols and recommendations of the vendor with topic or systemic antibiotics as indicated.

\section{Chemotherapy}

Carboplatin and 5-FU are given on days 8-12 and 36-40 (corresponding to radiotherapy-week 1 and 5). Carboplatin is prescribed at $70 \mathrm{mg} / \mathrm{m}^{2}$ body surface as a onehour intravenous infusion, 5 -FU at $600 \mathrm{mg} / \mathrm{m}^{2}$ of body surface as continuous infusion over 23 hours. Patients are provided with standard antiemetic prophylaxis and hydration according to institutional protocols.

\section{Treatment planning and radiotherapy}

Patients are immobilized using individual thermoplastic head masks incl. shoulder fixation (HeadStep ${ }^{\circledR}$, ITV), planning examinations include CT-scan and contrast enhanced MRI for 3D image correlation. Target volumes are delineated in accordance with current guidelines and recommendations [16-18].

All patients are treated with inversely-planned intensity-modulated radiotherapy (IMRT) either at a $6 \mathrm{MV}$ linear accelerator in step-and-shoot technique or at a $6 \mathrm{MV}$ tomotherapy unit under regular image guidance.

A dose of 50.4 Gy in daily fractions of 1.8 Gy (Monday to Friday) is prescribed to the neck (CTV 2). From study day 29 onwards, patients receive an additional fraction at 1.5 Gy per day in a classical concomitant boost regimen $[19,20]$ to a total dose of 69.9 Gy to the primary tumor and involved lymph nodes (CTV 1). There is at least a 6 -h-interval between the two daily fractions.

\section{Follow-up}

Regular follow up is carried out 6 weeks post treatment, 3 months (4-5 months post completion of therapy) thereafter, and then in 6 monthly intervals including fibreoptic examination and local imaging with MRI. In the presence 
of contra-indications, local imaging is carried out with contrast-enhanced CT scans.

\section{Study design and analysis}

$\mathrm{REACH}$ is a prospective, bi-centric, single-arm phase II trial of combined radiochemoimmunotherapy with weekly cetuximab, carboplatin and 5-FU (according to the Staar protocol [7]) and IMRT in a concomitant boost concept. Planned accrual is 60 patients.

Primary endpoint of the trial is local-regional control (LRC); secondary endpoints are disease-free survival (DFS), progression-free survival (PFS), overall survival (OS), acute and late radiation effects, adverse events. Control and survival data are calculated from administration of cetuximab loading dose.

Physical examination and monitoring of adverse events as well as routine hematologic and chemical blood analysis is performed weekly throughout the treatment period. Toxicity is assessed using NCI CTC v 3.0.

Evaluation of disease response is carried out according to the Response Evaluation Criteria in Solid Tumors (RECIST) [21] 6 weeks, 4-5 months, 6-7 months post completion of treatment and then in 6-monthly intervals. Further details can be found in the published trial protocol [15].

\section{Results}

Between August 2009 and March 2012, twenty-one patients were accrued to the REACH trial. Three patients subsequently had to be excluded from the trial: two patients had to be excluded due to poor compliance prior to treatment start, another patient developed an anaphylactic reaction to the trial medication on first exposure to cetuximab and had to discontinue treatment within the trial. Eighteen patients with a median age of 57 years (43 -69) are treated within the protocol, fourteen patients have completed treatment. Most patients had very advanced disease not accessible to surgical treatment. Fifteen out of 18 patients were male, all patients had a history of heavy smoking. Fourteen patients completed trial treatment as scheduled. Median dose to the cervical lymph nodes was 50 Gy $(49-51)$, the primary and involved lymph nodes received a median total dose of 70 Gy (69 - 74 Gy). Median follow-up from cetuximab loading dose excluding patients still under treatment $(\mathrm{n}=$ 14 ) is 17.4 months (6.5 - 30 months). Baseline characteristics are displayed in Table 1.

Treatment was generally tolerated well with the most common side effects being the typical, cetuximabinduced acneiforme skin rash, mucositis, dysphagia, dermatitis, and xerostomia. No chemotherapy cycle had to be postponed or dose-reduced due to toxicity, acneiforme rash was mostly moderate and did not lead to treatment interruptions or dose changes. Twelve out of 18 patients
Table 1 Patient baseline and treatment characteristics; patients still under therapy are not included in followup/outcome analysis

\begin{tabular}{|c|c|c|}
\hline characteristic & & range \\
\hline median age (years), $n=18$ & 57 & $\begin{array}{l}44- \\
69\end{array}$ \\
\hline $\begin{array}{l}\text { median follow-up (months), } \mathbf{n}=14 \text { excluding pts } \\
\text { under treatment }\end{array}$ & 17.4 & $\begin{array}{l}6.5- \\
30\end{array}$ \\
\hline deceased (pts) & 1 & \\
\hline male (pts) & 16 & \\
\hline female (pts) & 5 & \\
\hline \multicolumn{3}{|l|}{ Site $(n=18)$} \\
\hline palate (pts) & 2 & \\
\hline oropharynx & 7 & \\
\hline hypopharynx & 6 & \\
\hline larynx & 3 & \\
\hline \multicolumn{3}{|l|}{ Stage $(n=18)$} \\
\hline $\mathrm{T} 2$ & 3 & \\
\hline T3 & 8 & \\
\hline T4 & 7 & \\
\hline NO & 2 & \\
\hline $\mathrm{N} 2 \mathrm{~b}$ & 4 & \\
\hline $\mathrm{N} 2 \mathrm{C}$ & 11 & \\
\hline N3 & 1 & \\
\hline \multicolumn{3}{|l|}{ therapy $(n=14)$} \\
\hline median dose (cervical lymph nodes)/Gy & 50 & $\begin{array}{c}49- \\
51\end{array}$ \\
\hline median dose (primary and involved nodes)/Gy & 20 & $\begin{array}{c}19- \\
24\end{array}$ \\
\hline median total dose/Gy & 70 & $\begin{array}{l}69- \\
74\end{array}$ \\
\hline
\end{tabular}

received a prophylactic feeding tube prior to therapy start, however, only one patient was feeding tube dependent during therapy. A list of observed side effects can be found in Table 2.

There were six serious adverse events, three events were judged unrelated to the trial treatment: one patient has deceased due to systemically progressive disease $\left(\mathrm{CTC}{ }^{\circ} \mathrm{V}\right)$, one patient was hospitalized for treatment of tonsillitis (CTC $\left.{ }^{\circ} \mathrm{III}\right) 6$ months after completion of therapy, and one patient developed septic shock of unknown genesis more than 6 months post completion of therapy, and had a protracted, complicated hospital stay. One patient was diagnosed with an abdominal wall abscess under therapy, which had also occurred several times in the past prior to trial treatment; relatedness to the trial medication is therefore questionable but cannot be excluded. Another patient developed an iliac artery embolism and consequently had to undergo surgery. This patient did not have any history of embolic events, no cardiac arrhythmias or any other predisposing factors. 
Table 2 Treatment adverse events ( $n=14$ pts)

\begin{tabular}{|c|c|c|c|c|c|}
\hline \multirow[t]{2}{*}{$\begin{array}{l}\text { adevers events } \\
\text { (AEs), } n=14\end{array}$} & \multicolumn{5}{|c|}{ severity (CTC v. 3) grade } \\
\hline & 1 & II & III & IV & V \\
\hline acneiforme skin rash & $5(35.7 \%)$ & $9(64.3 \%)$ & $1(7.1 \%)$ & & \\
\hline conjunctivitis & & $1(7.1 \%)$ & & & \\
\hline skin fissures & $1(7.1 \%)$ & $1(7.1 \%)$ & & & \\
\hline mucositis & $2(14.3 \%)$ & $8(57.1 \%)$ & $4(28.6 \%)$ & & \\
\hline dysphagia & $5(35.7 \%)$ & $7(50 \%)$ & $1(7.1 \%)$ & & \\
\hline weight loss & $1(7.1 \%)$ & $1(7.1 \%)$ & & & \\
\hline dermatitis & $2(14.3 \%)$ & $6(42.9 \%)$ & $2(14.3 \%)$ & & \\
\hline xerostomia & $8(57.1 \%)$ & $5(35.7 \%)$ & & & \\
\hline laryngeal oedema & $3(21.4 \%)$ & & & & \\
\hline anemia & & $1(7.1 \%)$ & & & \\
\hline leukopenia & & & $1(7.1 \%)$ & & \\
\hline thrombopenia & & & & $1(7.1 \%)$ & \\
\hline fever & $1(7.1 \%)$ & $1(7.1 \%)$ & & & \\
\hline hyperkalaemia & $1(7.1 \%)$ & & & & \\
\hline hypokalaemia & & & $2(14.3 \%)$ & & \\
\hline hypomagnesiaemia & $3(21.4 \%)$ & & & & \\
\hline nausea & $5(35.7 \%)$ & & & & \\
\hline oedema & $7(50 \%)$ & & & & \\
\hline diarrhoea & $3(21.4 \%)$ & & & & \\
\hline constipation & $5(35.7 \%)$ & & & & \\
\hline \multicolumn{6}{|c|}{ Serious adverse events (SAEs) } \\
\hline skin abscess & & & $1(7.1 \%)$ & & \\
\hline arterial embolism & & & $1(7.1 \%)$ & & \\
\hline septic shock & & & $1(7.1 \%)$ & & \\
\hline anaphylactic reaction & & & $1(7.1 \%)$ & & \\
\hline hospital admission du & & & $1(7.1 \%)$ & & \\
\hline death due to progress & atic disease & & & & $1(7.1 \%)$ \\
\hline
\end{tabular}

Relationship of this event with the trial treatment is therefore possible. There was one anaphylactic reaction to cetuximab at first exposure leading to discontinuation of trial treatment. All patients recovered from the adverse events.

Acute toxicity commonly observed in patients receiving chemoradiation is resolving rapidly so far, residual mucositis on the first follow-up (6 weeks post treatment) was seen in $7 / 14$ patients. Dysphagia was generally resolving fast, 3 patients so far had evidence of dysphagia at the second follow-up. One patient with large mediastinal lymph node metastasis was still feeding-tube dependent though this is not attributable to study treatment. There is no higher-grade xerostomia, no evidence of highergrade late effects have been found so far (Table 3 ).

Treatment response is promising, first follow-up controls are available in 14 out of 18 patients treated within the protocol. Figures 1, 2, 3, 4 show a patient with a complete remission already at the first follow-up. While $4 / 14$ patients showed complete remissions on their first follow-up, 8/14 patients had a CR on their second followup visit (approx. 4-5 months post completion of treatment). There was no planned prophylactic neck dissection after completion of treatment, one patient only has yet had to undergo neck dissection for residual nodal disease. Pathology of the neck dissection revealed no vital tumour cells. Six patients underwent microlaryngoscopy or panendoscopy and probe excision after a median of 5.5 months [ 2.9 - 26.3 months] post treatment. None of the samples showed any evidence of malignancy. Two patients only showed stable disease on their first followup. One developed a CR on his next visit, the other also had a distant disease progression and received palliative chemotherapy. This patient has deceased six months post completion of treatment. Only two further patients with a complete remission at the primary site developed 
Table 3 Resolution of treatment-related side effects on follow-up ( $n=14$ )

\begin{tabular}{|c|c|c|c|c|}
\hline $\begin{array}{l}\text { typical side } \\
\text { effects }\end{array}$ & $\begin{array}{l}\text { CTC } \\
\text { grade }\end{array}$ & $\begin{array}{l}\text { end of treatment }(\mathrm{N}= \\
\text { 14) }\end{array}$ & $\begin{array}{l}6 \text { weeks post completion of treatment, } \\
\mathrm{N}=14\end{array}$ & $\begin{array}{l}\text { 4-5 months post completion of treatment, } \\
\mathrm{N}=14\end{array}$ \\
\hline \multirow[t]{3}{*}{ mucositis } & I & $2(14.3 \%)$ & $5(35.7 \%)$ & $3(21.4 \%)$ \\
\hline & $\|$ & 8 (57.1\%\%) & $2(14.3 \%)$ & \\
\hline & III & $4(28.6 \%)$ & 0 & \\
\hline \multirow[t]{3}{*}{ dermatitis } & I & $2(14.3 \%)$ & $6(42.9 \%)$ & \\
\hline & $\|$ & $6(42.9 \%)$ & 0 & \\
\hline & III & 2 (14.3\%) & 0 & \\
\hline \multirow{3}{*}{$\begin{array}{l}\text { acneiforme skin } \\
\text { rash }\end{array}$} & 1 & $5(35.7 \%)$ & 1 (7.1\%) & \\
\hline & $\|$ & $9(64.3 \%)$ & 0 & \\
\hline & III & $1(7.1 \%)$ & 0 & \\
\hline \multirow[t]{3}{*}{ dysphagia } & I & $5(35.7 \%)$ & 4 (28.6\%) & \\
\hline & $\|$ & $7(50 \%)$ & 9 (64.3\%) & $3(21.4 \%)$ \\
\hline & III & 1 (7.1\%) & 1 (7.1\%) & 1 (7.1\%) \\
\hline \multirow[t]{2}{*}{ xerostomia } & I & $8(57.1 \%)$ & 9 (64.3\%) & $10(71.4 \%)$ \\
\hline & ॥ & 5 (35.7\%) & $2(14.3 \%)$ & 1 (7.1\%) \\
\hline
\end{tabular}

distant disease (pulmonary metastases, osseous metastasis) after treatment, one received systemic chemotherapy according to the EXTREME regimen [22], the other received local irradiation for solitary osseous metastasis. Both are stable without further treatment (Table 4).

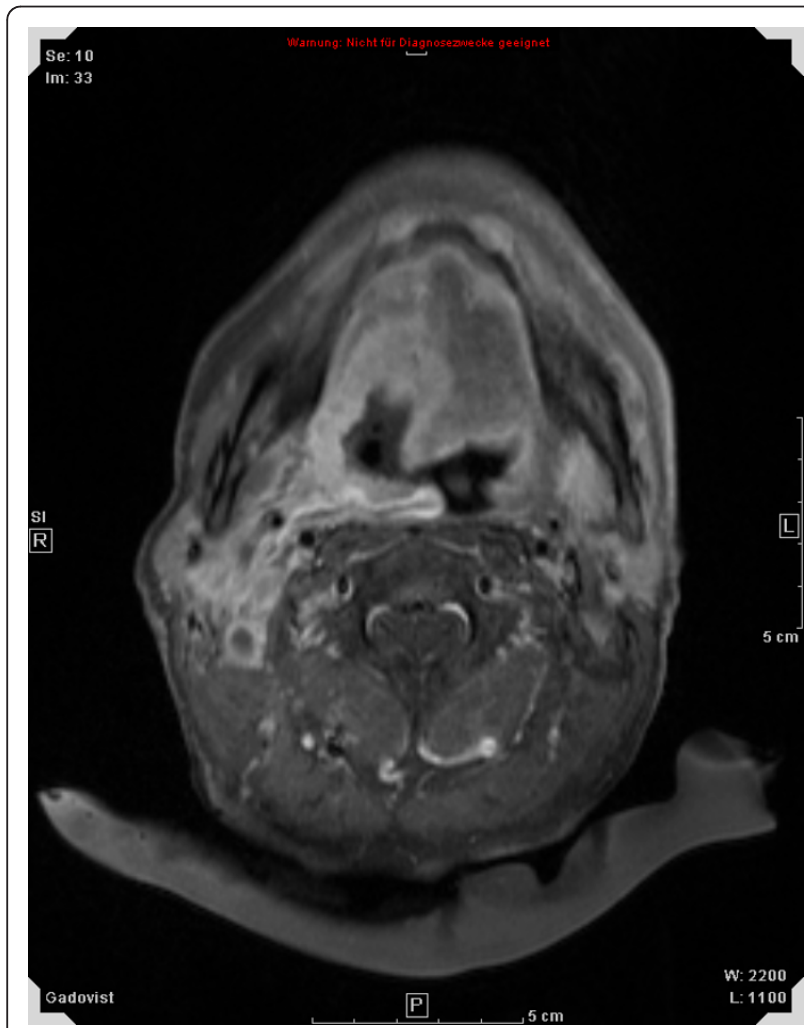

Figure 150 y old patient with oro-/hypopharyngeal carcinoma; planning MRI.
Median progression-free survival (PFS) has therefore not yet been reached, overall progression-free survival at one year is currently $84.4 \%$ (Figure 5 ). Swallowing rehabilitation was successful in 13 out of the 14 patients, one

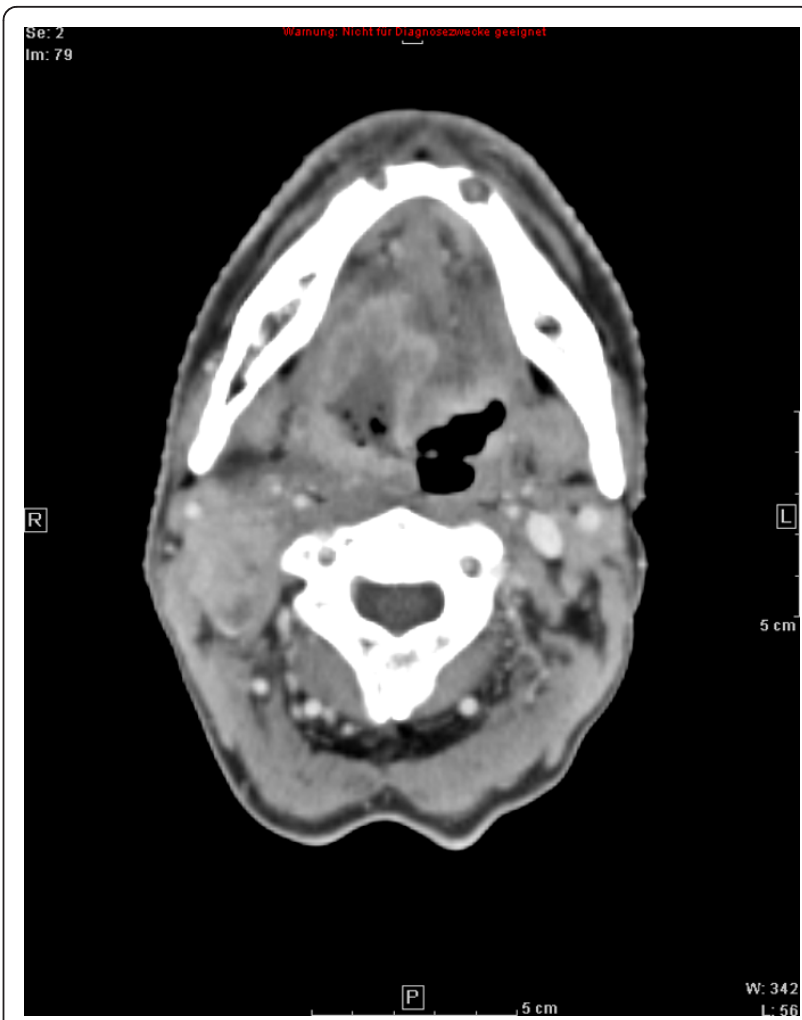

Figure 250 y old patient with oro-/hypopharyngeal carcinoma; planning $\mathrm{CT}$. 


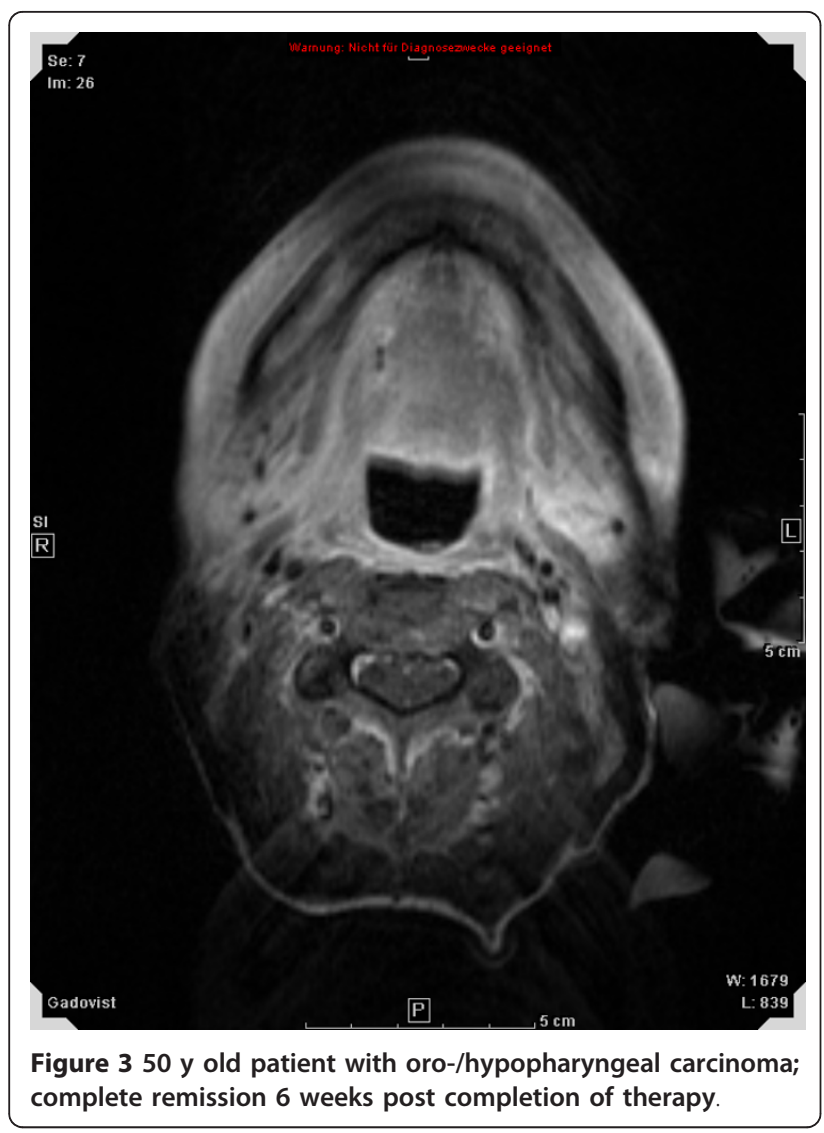

patient had a persistent swallowing dysfunction due to distant metastatic disease with a large mediastinal mass.

\section{Discussion}

REACH combines the use of modern radiotherapeutic techniques (IMRT), altered fractionation (accelerated/ hyperfractionated treatment), and systemic agents (concomitant radiochemotherapy with carboplatin/5-FU and the EGFR antibody cetuximab) in order to improve local control and ultimately patient outcome.

While treatment intensity with both the use of radiochemotherapy, immunotherapy, and concomitant boost is high, protocol treatment is tolerated reasonably well and without treatment delays. The combination of carboplatin and 5-FU has been shown to achieve similar results as cisplatin $100 \mathrm{mg} / \mathrm{m}^{2} \mathrm{q} 3$ weeks with a more favourable toxicity profile and subsequently higher patient compliance [7]. Bone marrow toxicity with grade III and IV (2/14 pts, $14.3 \%)$ was rare in our data and not higher than in our reference protocol [7]. Mucositis rates were moderate with no grade IV mucositis and $85.7 \%$ mucositis grade II and III. Observed mucositis rates are lower than in reported in the standard chemotherapy protocol where $68 \%$ mucositis grade III and IV were seen [7]. Mucositis rates in the landmark trials for definitive radiochemotherapy of locally

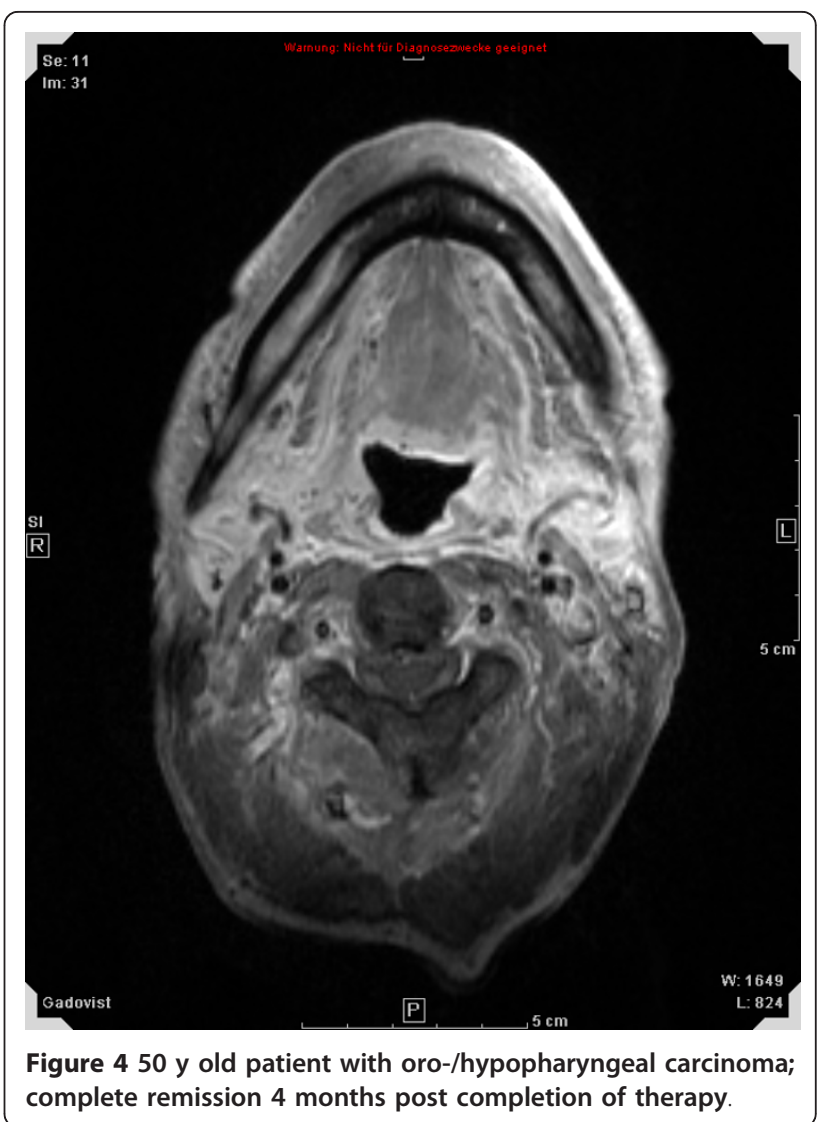

advanced SCCHN vary widely between 12.8 and $77 \%$ grade III mucositis, most report rates roughly between 50 and 70\% [7,23-27]. However, these trials mostly employed conventional radiotherapy techniques as IMRT was not the standard at the time, therefore our low mucositis rates may be attributable to the use of IMRT in our trial. Recent phase II trials also employing combined radiochemotherapy regimen and IMRT also report a lower incidence of grade III and grade IV mucositis between 29 and 38\% [28-30]. Also, the rates of severe dysphagia of one in 14 patients $(7.1 \%)$ and dysphagia CTC grade II (50\%) in $\mathrm{REACH}$ is very low in comparison with rates published in the large phase III trials (31 - 44\% dysphagia CTC grade III, [23,24,27]). Again, intensity-modulated radiotherapy trials report lower rates of severe dysphagia between $7 \%$ and 28\% [28-30] supports the observation of the REACH trial.

Addition of cetuximab to chemoradiation with carboplatin/5-FU so far lead to a rather moderate, increased skin toxicity: acneiforme rash CTC grade II/III was present in $10 / 14$ patients $(71.4 \%)$ and correlates well with the observations by Bonner and colleagues $[8,9]$ using conventional radiation techniques and $11-67 \%$ reported in the combined regimen using IMRT [29-31]. No cetuximab-specific exfoliations occurred so far. No grade IV and only one 
Table 4 Treatment response

\begin{tabular}{llll}
\hline Local response & $\begin{array}{l}\mathbf{6} \text { weeks post completion of treatment [pts, } \\
(\%)], \mathbf{N}=\mathbf{1 4}\end{array}$ & $\begin{array}{l}\mathbf{4 - 5} \text { months post completion of treatment } \\
\text { [pts, (\%)], } \mathbf{N = 1 4}\end{array}$ & $\begin{array}{l}\text { at time of analysis [pts, } \\
(\%)] \mathbf{N}=\mathbf{1 4}\end{array}$ \\
\hline CR & $4(28.6 \%)$ & $8(57.1 \%)$ & $13(92.9 \%)$ \\
\hline PR & $8(57.1 \%)$ & $5(35.7 \%)$ & 0 \\
\hline SD & $2(14.3 \%)$ & $1(7.1 \%)$ & $1(7.1 \%)$ \\
\hline PD (locoregional) & 0 & 0 & 0 \\
\hline PD (distant & 0 & $1(7.1 \%)$ & $3(21.4 \%)$ \\
metastases) & & & \\
\hline
\end{tabular}

grade III cetuximab- induced skin toxicity was observed in the REACH protocol suggesting that our standard skin care protocols in accordance with the recommendations by the vendour help preventing major complications [32].

Response rates in the triple combination regimen are promising so far: two patients only had stable disease on their first follow-up after treatment corresponding to an overall objective response rate of $85.7 \%$ (CR: $28.6 \%$, PR: $57.1 \%)$. One patient with stable disease had developed complete remission 4-5 months post completion of treatment, the other patient with stable disease on the first follow-up was diagnosed with distant metastases and has deceased 6 months post completion of the REACH regimen. $\mathrm{REACH}$ response rates are in the range of rates reported by other groups evaluating the combination of chemotherapy and cetuximab in the definitive setting $[30,31,33]$ even though most of our patients had very advanced disease and therefore represent a very negative pre-selection. Interestingly though, theses protocols also carried out planned neck dissections irrespective of remission status post completion of treatment. Notably, most REACH patients showed partial remissions six weeks post completion of therapy and had developed complete remissions on the second follow-up three months afterwards

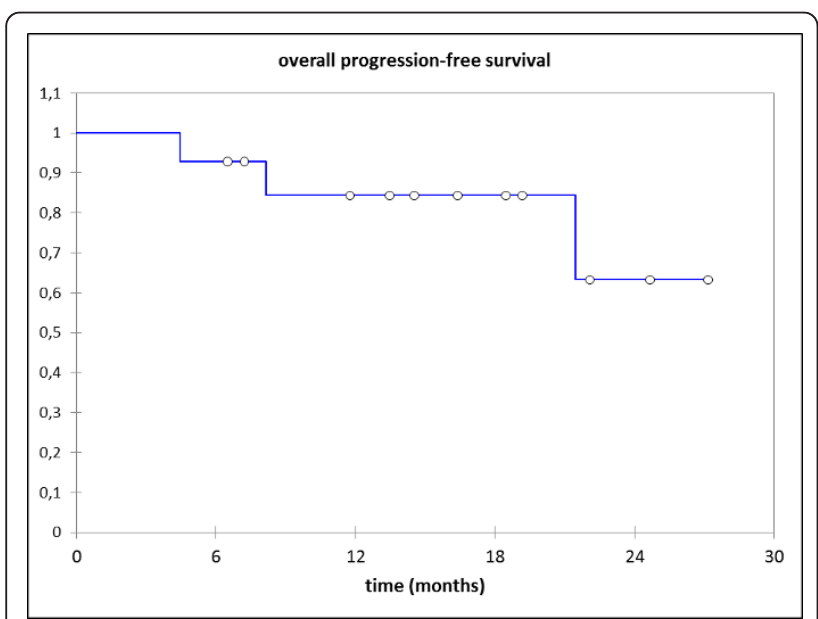

Figure 5 Overall progression-free survival (PFS) $(n=14$ pts) PFS at 1 year: $84.4 \%$; PFS at 2 years $63.3 \%$. reflecting the fact that tumour response may take longer than just 4-6 weeks after therapy. Our observation is supported by Beckmann and co-workers who saw only $16 \%$ complete remissions at the first follow-up and 73\% thereafter [34]. Prevalence and influence of HPV in our cohort is currently under investigation.

We had six reported serious adverse events, for three of them there is (anaphylactic reaction) or may be a relationship to the trial medication (abdominal wall abscess, arterial embolism), all of these patients recovered uneventfully from the adverse event, hence discontinuation of the trial was not warranted.

So far, five phase II trials using chemotherapy, cetuximab and mostly IMRT are reported. Apart from Pfister et al., all of them were completed as scheduled and did not observe any unexpected toxicity [28-30,33], hence the combination of chemotherapy, cetuximab, and modern radiotherapy techniques seems feasible and the use of IMRT in a standard concomitant boost concept to reduce overall treatment time and reduce tumor cell repopulation $[4,6,19]$ is practicable. Long-expected results of the randomized RTOG 0522 phase III trial comparing radiochemotheray $+/$ - cetuximab have recently been presented: so far, there is no significant difference between the two treatment arms could be found with regard to progression-free survival and overall survival. There seems to be a trend toward higher distantmetastasis-free survival in the experimental arm (radiochemoimmunotherapy). Many patients have not yet even reached median follow-up, subgroup analyses regarding the influence of radiotherapy technique (accelerated radiotherapy (3D) vs IMRT) has not yet been published and is yet unclear [35]. Therefore it is too early to draw any conclusions from this trial.

Unfortunately patient accrual to the REACH trial is rather slow reflecting the fact that treatment of locally advanced SCCHN is still primarily surgical in Germany. However, functional outcome in of conservative treatment strategies as reflected in the REACH trial is excellent, apart from the patient with distant progressive disease and mediastinal mass, treatment related dysphagia has rapidly recovered post treatment. To date, there has been no case of swallowing dysfunction. 


\section{Conclusion}

The combination of our standard radiochemotherapy regimen with carboplatin/5-FU and cetuximab is feasible resulting in promising objective response rates. Also the use of a classical concomitant boost concept in intensitymodulated technique has been shown to be practicable in a routine clinical setting resulting in only moderate overall toxicity of the regimen. However, patient accrual needs to be improved.

\section{Financial support}

Supported by a project grant from Merck KGaA, Darmstadt, Germany

\section{Author details \\ 'Dept of Radiation Oncology, University of Heidelberg, INF 400, 69120 Heidelberg, Germany. ${ }^{2}$ Dept of Radiation Oncology, INF 400, 69120 Heidelberg, Germany. ${ }^{3}$ National Centre for Tumour Disease (NCT), INF 460, 69120 Heidelberg, Germany. ${ }^{4}$ Dept of Head and Neck Surgery, INF 400, 69120 Heidelberg, Germany.}

\section{Authors' contributions}

$A D J, J K, C S$, and MWM are responsible for patient accrual, ADJ, AVN, KP, MWM for patient treatment, ADJ, JK, CS, and MWM for patient follow-up. MWM and JD were responsible for concept and design of the trial. ADJ, $A V N$, and $K L$ coordinated and organized the trial. All authors read and approved the final manuscript.

\section{Competing interests}

$J D$ is a member of the Merck KGaA advisory board. All other authors declare that they have no competing interests.

Merck Serono has reviewed the publication, views and opinions described do not necessarily reflect those of Merck Serono.

Received: 11 December 2011 Accepted: 2 April 2012

Published: 2 April 2012

\section{References}

1. Pignon JP, Bourhis J, Domenge C, Designe L: Chemotherapy added to locoregional treatment for head and neck squamous-cell carcinoma: three meta-analyses of updated individual data. Lancet 2000, 355:949-955.

2. Pignon JP, le Maitre A, Bourhis J: MACH-NC Collaborative Group. Metaanalysis of chemotherapy in head and neck cancer (MACH-NC): an update. Int J Radiat Oncol Biol Phys 2007, 69:S112-114.

3. Pignon JP, le Maitre A, Maillard E, Bourhis J: MACH-NC Collaborative Group. Meta-analysis of chemotherapy in head and neck cancer (MACHNC): an update on 93 randomised trials and 17,346 patients. Radiother Oncol 2009, 92:4-14.

4. Bourhis J, Overgaard J, Audry H, Ang KK, Saunders M, Bernier J, Horiot JC, Le Maître A, Pajak TF, Poulsen MG, O'Sullivan B, Dobrowsky W, Hliniak A, Skladowski K, Hay JH, Pinto LH, Fallai C, Fu KK, Sylvester R, Pignon JP, MetaAnalysis of Radiotherapy in Carcinomas of Head and neck (MARCH) Collaborative Group: Hyperfractionated or accelerated radiotherapy in head and neck cancer: a meta-analysis. Lancet 2006, 368:843-854.

5. Budach W, Hehr T, Budach V, Belka C, Dietz K: A meta-analysis of hyperfractionated and accelerated radiotherapy and combined chemotherapy and radiotherapy regimens in unresected locally advanced squamous cell carcinoma of the head and neck. BMC Cancer 2006, 6:28.

6. Fu KK, Pajak TF, Trotti A, Jones CU, Spencer SA, Phillips TL, Garden AS, Ridge JA, Cooper JS, Ang KK: A radiation therapy oncology group (RTOG) phase III randomized study to compare hyperfractionation and two variants of accelerated fractionation to standard fractionation radiotherapy for head and neck squamous cell carcinomas: first report of RTOG 9003. Int J Radiat Oncol Biol Phys 2000, 48:7-16.
7. Staar S, Rudat V, Stuetzer H, Dietz A, Volling P, Schroeder M, Flentje M Eckel HE, Mueller RP: Intensified hyperfractionated accelerated radiotherapy limits the additional benefit of simultaneous chemotherapy - results of a multicentric randomized German trial in advanced headand-neck cancer. Int J Radiat Oncol Biol Phys 2001, 50:1161-1171.

8. Bonner JA, Harari PM, Giralt J, Azarnia N, Shin DM, Cohen RB, Jones CU, Sur R, Raben D, Jassem J, Ove R, Kies MS, Baselga J, Youssoufian H, Amellal N, Rowinsky EK, Ang KK: Radiotherapy plus cetuximab for squamous-cell carcinoma of the head and neck. N Engl J Med 2006 , 354:567-578.

9. Bonner JA, Harari PM, Giralt J, Cohen RB, Jones CU, Sur RK, Raben D, Baselga J, Spencer SA, Zhu J, Youssoufian H, Rowinsky EK, Ang KK Radiotherapy plus cetuximab for locoregionally advanced head and neck cancer: 5-year survival data from a phase 3 randomised trial, and relation between cetuximab-induced rash and survival. Lancet Oncol 2010, 11:21-28

10. Caudell JJ, Sawrie SM, Spencer SA, Desmond RA, Carroll WR, Peters GE, Nabell LM, Meredith RF, Bonner JA: Locoregionally advanced head and neck cancer treated with primary radiotherapy: a comparison of the addition of cetuximab or chemotherapy and the impact of protocol treatment. Int J Radiat Oncol Biol Phys 2008, 71:676-681.

11. Nutting CM, Morden JP, Harrington KJ, Urbano TG, Bhide SA, Clark C, Miles EA, Miah AB, Newbold K, Tanay M, Adab F, Jefferies SJ, Scrase C, Yap BK, A'Hern RP, Sydenham MA, Emson M, Hall E: PARSPORT trial management group. Parotid-sparing intensity modulated versus conventional radiotherapy in head and neck cancer (PARSPORT): a phase 3 multicentre randomised controlled trial. Lancet Oncol 2011, 12:127-136.

12. Münter MW, Hoffner $S$, Hof H, Herfarth KK, Haberkorn U, Rudat $V$, Huber $P$, Debus J, Karger CP: Changes in salivary gland function after radiotherapy of head and neck tumors measured by quantitative pertechnetate scintigraphy: comparison of intensity-modulated radiotherapy and conventional radiation therapy with and without amifostine. Int J Radiat Oncol Biol Phys 2007, 67:651-659.

13. Münter MW, Karger CP, Hoffner SG, Hof H, Thilmann C, Rudat V, Nill S, Wannenmacher $M$, Debus J: Evaluation of salivary gland function after treatment of head-and-neck tumors with intensity-modulated radiotherapy by quantitative pertechnetate scintigraphy. Int J Radiat Oncol Biol Phys 2004, 58:175-184.

14. Clavel S, Nguyen D, Despres P, Fortin B, Coulombe G, Donath D, Soulieres D, Charpentier D, Guertin L, Nguyen-Tan PF: Higher dose per fraction and shorter overall treatment time using intensity-modulated radiation therapy versus conventional radiation therapy with concurrent carboplatin and 5-fluorouracil for locally advanced oropharyngeal carcinoma: a comparison of toxicity and efficacy. J Clin Oncol 2009, 27:15, suppl; abstr 6038.

15. Habl G, Jensen AD, Potthoff $K$, Uhl M, Hof H, Hajda J, Simon C, Debus J, Krempien R, Münter MW: Treatment of locally advanced carcinomas of the head and neck with intensity-modulated radiation therapy (IMRT) in combination with cetuximab and chemotherapy: the REACH protocol. BMC Cancer 2010, 10:651

16. Gregoire V, Eisbruch A, Hamoir M, Levendag P: Proposal for the delineation of the nodal CTV in the node-positive and the postoperative neck. Radiother Oncol 2006, 79:15-20.

17. Levendag P, Braaksma M, Coche E, Van Der Est H, Hamoir M, Muller K, Noever I, Nowak P, van Sörensen De Koste J, Grégoire V,

Brussels Rotterdam: CT-based neck nodal delineation compared with the surgical levels as defined by the American academy of otolaryngologyhead and neck surgery. Int J Radiat Oncol Biol Phys 2004, 58:113-123.

18. Poon I, Fischbein N, Lee N, Akazawa P, Xia P, Quivey J, Phillips T: A population-based atlas and clinical target volume for the head-and-neck lymph nodes. Int J Radiat Oncol Biol Phys 2004, 59:1301-1311.

19. Ang KK, Harris J, Garden AS, Trotti A, Jones CU, Carrascosa L, Cheng JD, Spencer SS, Forastiere A, Weber RS: Concomitant boost radiation plus concurrent cisplatin for advanced head and neck carcinomas: Radiation Therapy Oncology Group Phase II trial 99-14. J Clin Oncol 23:3008-3015.

20. Garden AS, Harris J, Trotti A, Jones CU, Carrascosa L, Cheng JD, Spencer SS, Forastiere A, Weber RS, Ang KK: Long-term results of concomitant boost radiation plus concurrent cisplatin for advanced head and neck carcinomas: ma phase II trial of the Radiation Therapy Oncology Group. Int J Radiat Oncol Biol Phys 2008, 71:1351-1355. 
21. Therasse P, Arbuck SG, Eisenhauer EA, Wanders J, Kaplan RS, Rubinstein L, Verweij J, Van Glabbeke M, van Oosterom AT, Christian MC, Gwyther SG: New guidelines to evaluate the response to treatment in solid tumors. J Natl Cancer Inst 2000, 92:205-216.

22. Vermorken JB, Mesia R, Rivera F, Remenar E, Kawecki A, Rottey S, Erfan J, Zabolotnyy D, Kienzer HR, Cupissol D, Peyrade F, Benasso M, Vynnychenko I, De Raucourt D, Bokemeyer C, Schueler A, Amellal N, Hitt R: Platin-based chemotherapy plus cetuximab in head and neck cancer. New Engl J Med 2008, 359:1116-1127.

23. Brizel DM, Albers ME, Fisher SR, Scher RL, Richtsmeier WJ, Hars V, George SL, Huang AT, Prosnitz LR: Hyprefractionated irradiation with or without cocncurrent chemotherapy for locally advanced head and neck cancer. New Engl J Med 1998, 338:1798-1804.

24. Calais $G$, Alfonsi $M$, Bardet $E$, Sire $C$, Germain $T$, Bergerot $P$, Rhein $B$, Tortochaux J, Oudinot P, Bertrand P: Randomized trial of radiation therapy versus concomitant chemohterapiy and radiation therapy für advancedstage oropharynx carcinoma. J Natl Cancer Inst 1999, 91:2081-2086.

25. Budach V, Stuschke M, Budach W, Baumann M, Geismar D, Grabenbauer G, Lammert I, Jahnke K, Stueben G, Herrmann T, Bamberg M, Wust P, Hinkelbein W, Wernecke KD: Hyperfractionated accelerated chemoradiation with concurrent fluorouracil-mitomycin is more effective than dose-escalated hyperfractionated accelerated radiation therapy alone in locally advanced head and neck cancer: final results of the radiotherapy kooperative clinical trials group of the German Cancer Society 95-06 prospective randomized trial. J Clin Oncol 2005, 23:1125-1135.

26. Adelstein DJ, Li Y, Adams GL, Wagner H Jr, Kish JA, Ensley JF, Schuller DE, Forastiere AA: An Intergroup phase III comparison of standard radiation therapy and two schedules of concurrent chemoradiotherapy in patients with unresectable squamous cell head and neck cancer. J Clin Oncol 2003, 21:92-98.

27. Huguenin P, Beer KT, Allal A, Rufibach K, Friedli C, Davis JB, Pestalozzi B, Schmid S, Thöni A, Ozsahin M, Bernier J, Töpfer M, Kann R, Meier UR, Thum P, Bieri S, Notter M, Lombriser N, Glanzmann C: Concomitant cisplatin significantly improves locoregional control in advanced head and neck cancers treated with hyperfractionated radiotherapy. J Clin Oncol 2003, 22:4665-4673.

28. Maguire PD, Papagikos M, Hamann S, Neal C, Meyerson M, Hayes N, Ungaro P, Kotz K, Couch M, Pollock H, Tepper J: Phase II trial of hyperfractionated intensity-modulated raidation therapy and concurrent weekly cispltin for stage III and IVa head-and-neck cancer. Int J Radiat Oncol Biol Phys 2011, 79:1081-1088.

29. Kao J, Genden EM, Gupta V, Policarpio EL, Burri RJ, Rivera M, Gurudutt V, Som PM, Teng M, Packer SH: Phase 2 trial of concurrent 5-fluorouracil, hydroxyurea, cetuximab, and hyperfractionated intensity-modulated radiation therapy for locally advanced head and neck cancer. Cancer 2011, 117:318-326

30. Merlano M, Russi E, Benasso M, Corvò R, Colantonio I, Vigna-Taglianti R, Vigo V, Bacigalupo A, Numico G, Crosetto N, Gasco M, Lo Nigro C, Vitiello R, Violante S, Garrone O: Cisplatin-based chemoradiation plus cetuximab in locally advanced head and neck cancer: a phase II clinical study. Ann Oncol 2011, 22:712-717.

31. Pfister DG, Su YB, Kraus DH, Wolden SL, Lis E, Aliff TB, Zahalsky AJ, Lake S, Needle MN, Shaha AR, Shah JP, Zelefsky MJ: Concurrent cetuximab, cisplatin, and concomitant boost radiotherapy for locoregionally advanced, squamous cell head and neck cancer: a pilot phase II study of a new combined-modality paradigm. J Clin Oncol 2006, 24:1072-1078.

32. Budach W, Bölke E, Homey B: Severe cutanous reaction during radiation therapy with concurrent cetuximab. N Engl J Med 2007, 357:514-515.

33. Koukourakis MI, Tsoutsou PG, Karpouzis A, Tsiarkatsi M, Karapantzos I, Daniilidis V, Kouskoukis C: Radiochemotherapy with cetuximab, cisplatin, and amifostine for locally advanced head and neck cancer: a feasibility study. Int J Radiat Oncol Biol Phys 2010, 77:9-15.

34. Beckmann GK, Hoppe F, Pfreundner L, Flentje MP: Hyperfractionated accelerated radiotherapy in combination with weekly cisplatin for locally advanced head and neck cancer. Head Neck 2005, 27:26-43.

35. Ang KK, Zhang QE, Rosenthal DI, Nguyen-Tan P, Sherman EJ, Weber S, Galvin JM, Schwartz DL, El-Naggar AK, Gillison ML, Jordan R, List MA, Konski AA, Thorstad WL, Trotti A, Beitler JJ, Garden AS, Spanos WJ, Yom SS, Axelrodt RS: A randomized pahse III trial (RTOG 0522) of concurrent accelerated radiation plus cisplatin with or without cetuximab for stage
III-IV head and neck squamous cell carcinomas (HNC). J Clin Oncol 2011, 29, abstr. 5500 .

doi:10.1186/1748-717X-7-57

Cite this article as: Jensen et al:: Radiochemoimmunotherapy with intensity-modulated concomitant boost: interim analysis of the REACH trial. Radiation Oncology 2012 7:57.

\section{Submit your next manuscript to BioMed Central and take full advantage of:}

- Convenient online submission

- Thorough peer review

- No space constraints or color figure charges

- Immediate publication on acceptance

- Inclusion in PubMed, CAS, Scopus and Google Scholar

- Research which is freely available for redistribution 